\title{
The Hidden Face of Fear in the COVID-19 Era: The Amygdala Hijack
}

\author{
Nicola Morelli ${ }^{a, b}$ Eugenia Rota ${ }^{c}$ Paolo Immovilli ${ }^{a}$ Marco Spallazzi $^{d}$ Davide Colombi $^{b}$ \\ Donata Guidetti ${ }^{\mathrm{a}}$ Emanuele Michieletti ${ }^{\mathrm{b}}$

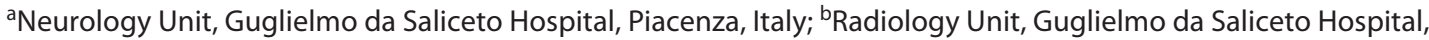

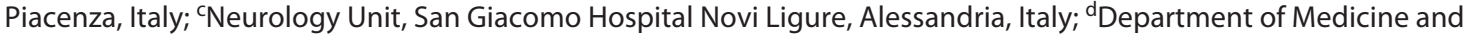 \\ Surgery, Section of Neurology Azienda Ospedaliero-Universitaria, Parma, Italy
}

Coronavirus (2019-nCoV) pandemic has placed an overwhelming health and economic burden [1] and, most likely, has had a dramatic impact on emotional regulation. An Italian 32-year-old healthy right-handed woman, resident in Piacenza, Italy, one of the red areas, underwent a functional MRI with a visual task where happy faces and threat-related cues were shown. Images of an intensive care unit correlated with a stronger activation of bilateral amygdala than did other tasks $(p<$ 0.05 , corrected) (Fig. 1). Indeed, when rating fear, the amygdala gives priority to $2019-\mathrm{nCoV}$ in people subjected to the psychological consequences of the pandemic. When emotion takes over, the amygdala hijack occurs [2].

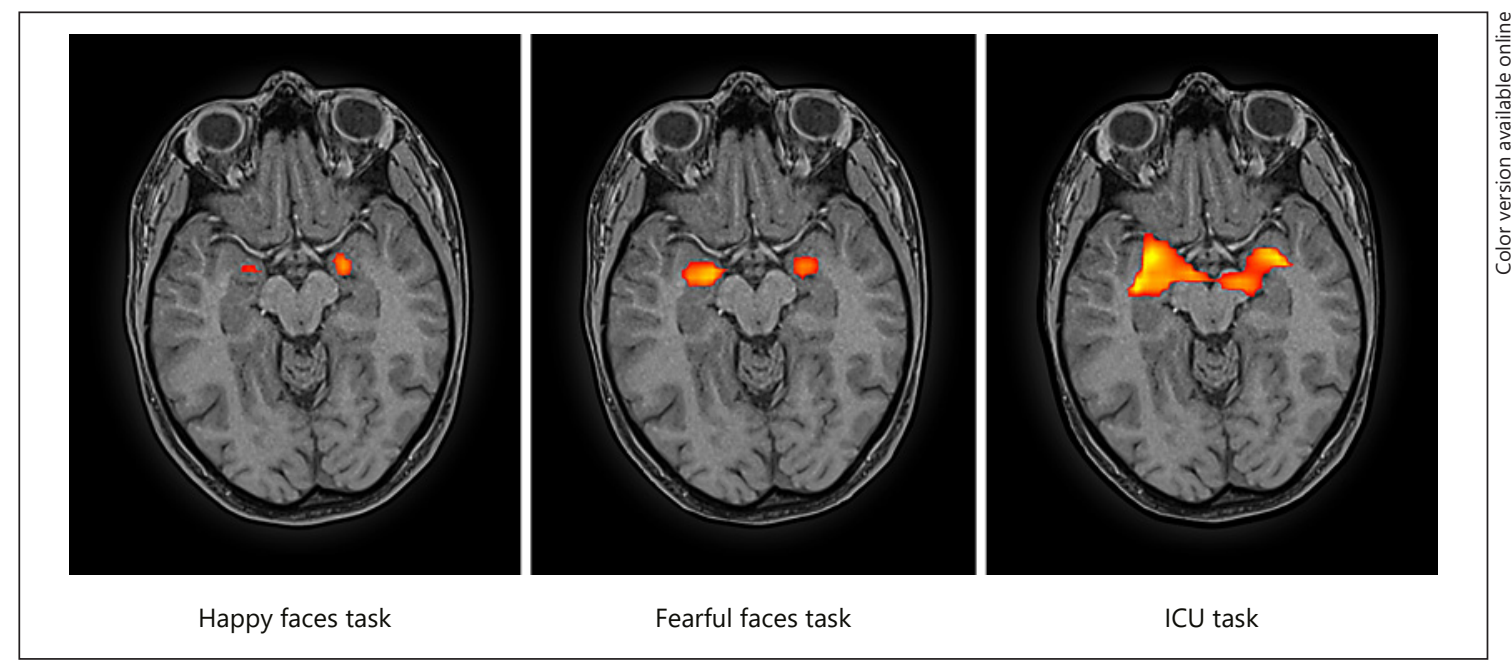

Fig. 1. Functional MRI. Tasks with happy faces and threat-related cues show a significant activation map (T-score 3-6) of the amygdalae, superimposed on a T1-weighted volumetric interpolated brain sequence. The ICU task involved images of intubated patients and healthcare personal with protective equipment, evoking the COVID-19 emergency and a stronger bilateral activation of the basolateral amygdala. ICU, intensive care unit.

karger@karger.com www.karger.com/ene

(C) 2020 S. Karger AG, Basel

\section{Karger!}

Dr. Nicola Morelli

Neurology and Radiology Unit, Guglielmo da Saliceto Hospital Via Taverna 49

IT-29121 Piacenza (Italy)

nicola.morelli.md@gmail.com 


\section{Acknowledgement}

The authors thank Mrs. Barbara Wade for her linguistic advice.

\section{Statement of Ethics}

Human and animal studies have been approved by the local Ethics Committee and, therefore, been performed in accordance with the ethical standards laid down in the 1964 Declaration of Helsinki and its later amendments. Specific national laws have been observed, too. The patient gave written informed consent for publication of the case, including brain MRI images.

\section{Disclosure Statement}

The authors declare that they have no conflicts of interest concerning this article.

\section{Funding Sources}

This research received no specific grant from any funding agency in the public, commercial, or not-for-profit sectors. No financial support was provided for the research, authorship, and/or publication of this article.

\section{Author Contributions}

Study concepts: N. Morelli and P. Immovilli. Study design: N. Morelli, M. Spallazzi, and D. Colombi. Data analysis/interpretation: N. Morelli. Manuscript preparation and definition of intellectual content: N. Morelli and E. Rota. Manuscript editing: N. Morelli and E. Rota. Manuscript revision/review: D. Guidetti and E. Michieletti.

References
1 Hick J, Biddinger P. Novel coronavirus and old lessons: preparing the health system for the pandemic. N Engl J Med. 2020 Mar 25. doi: 10.1056/NEJMp2005118. [Epub ahead of print].

2 Goleman, D. Emotional intelligence: why it can matter more than IQ. New York: Bantam Books; 1995. 